Pak. j. sci. ind. res. Ser. A: phys. sci. 201558 (2) 66-73

\title{
Electroless and Electrodeposition of Silver from a Choline Chloride-Based Ionic Liquid
}

\author{
Muhammad Rostom Ali ${ }^{\text {a*, }}$, Muhammad Ziaur Rahman and Siddhartha Sankar Saha ${ }^{\mathrm{b}}$ \\ ${ }^{a}$ Department of Applied Chemistry and Chemical Engineering, University of Rajshahi, Rajshahi-6205, Bangladesh \\ ${ }^{b}$ Department of Chemistry, Rajshahi University of Engineering and Technology, Rajshahi-6204, Bangladesh
}

(received June 26, 2013; revised March 24, 2013; accepted May 20, 2014)

\begin{abstract}
The electroless and electrolytic deposition of silver from a solution containing silver nitrate in either an ethylene glycol (EG)-choline chloride based or a urea-choline chloride based ionic liquids has been carried out onto steel and copper cathodes by simple immersion, constant current and constant potential methods at room temperature. It has been found that electroless silver deposits of up to several microns have been obtained by dip coating from both urea and EG based ionic liquids without the use of catalysts. The influences of various experimental conditions on electrodeposition and morphology of the deposited layers have been investigated by scanning electron microscopy (SEM) and X-ray diffraction (XRD). It has been observed that crack free bright metallic coloured silver coatings can be obtained from both EG and urea based ionic liquids at the applied deposition potentials up to $-0.40 \mathrm{~V}$ and applied deposition current densities up to $-5.0 \mathrm{~A} \mathrm{~m}^{-2}$ at room temperature. The cathodic current efficiency for the deposition of $\mathrm{Ag}$ is about $99 \%$.
\end{abstract}

Keywords: cyclic voltammetry, electrodeposition, electroless deposition, ethaline, reline, silver

\section{Introduction}

The electroless and electrodeposition of silver metal onto copper substrate is an important industrial process that is used primarily by the manufactures of printed circuit boards to prevent degradation of exposed copper surfaces (conduction tracks) during the time that elapses between the manufacture of the circuit board and the assembly procedure incorporating the board or component into a finished device. Typically this can be up to several months. This method of protection for copper surfaces is very effective despite the fact that silver is thermodynamically much more susceptible to aerobic oxidation. This is because silver oxide and sulphide (formed as tarnish on silver surfaces), as well as the underlying silver metal, are very soluble in the tin- and tin/lead-based molten solder that are used to bond the circuit components to the copper tracks of the circuit board.

On the contrary, copper oxides are poorly soluble in the molten solder such that, aerobic oxidation of the copper surface prior to soldering inhibits interfacial wetting at the copper/solder interface and prevents bonding of the component. In a practical device, this results in failure of the joint either through poor conductivity or because of low mechanical stress tolerance. Solder fluxes are often

*Author for correspondence; E-mail: dmrali@yahoo.com used to mitigate this problem by preventing aerobic oxidation of copper surfaces, but this approach is not always successful or practical. Commercial electroless silver processes typically use an aqueous $\mathrm{AgNO}_{3}$ solution in the presence of $\mathrm{HNO}_{3}$. In addition to the social and environmental concerns that surround the use of strong inorganic acids, here the use of $\mathrm{HNO}_{3}$, whilst necessary to the process, has an additional detrimental effect because there is competitive etching of the copper tracks during silver plating. This can be a serious problem for the electronics industry, particularly as integration densities continue to increase and consequently feature sizes become smaller. Many component failures arise because of copper etching (by the $\mathrm{HNO}_{3}$ ) before the surfaces are silver plated. In addition, the aqueous process requires the use of colloidal catalyst (usually palladium metal) to sustain silver plating from beyond a few nanometers up to 1-5 $\mu \mathrm{m}$ in thickness (Djokic et al., 2002; Shipley, 1961).

Sun et al. (2003) and Endres (2002) reported that, recently ionic liquids have received a great deal of attention in the literature as alternative solvents and electrolytes for a number of electrochemical processes. These processes range in scope from fundamental academic investigations, for example, into the structure of the solid/liquid interfaces (Ohno, 2005), or into the mechanisms of ion diffusion, to industrial processes where, the ionic liquid has the potential to replace conventional noxious aqueous media (Abbott 
et al., 2004a). A relatively new class of ionic liquid based on eutectic mixtures of choline chloride with a hydrogen bond donor species has been reported by Abbott and Mckenzie (2006) and Abbott et al. (2004b; 2003). Abbott et al. (2006a; 2006b) also reported that, these liquids can be used for deposition of a range of metal coatings including $\mathrm{Zn}, \mathrm{Cr}, \mathrm{Sn}, \mathrm{Cu}$, and $\mathrm{Ag}$ at high current efficiency and also for metal dissolution processes such as electropolishing. In many cases, the use of ionic liquids as solvents overcomes the need for strong inorganic acids (e.g., chromic acid, $\mathrm{HF}, \mathrm{H}_{3} \mathrm{PO}_{4}, \mathrm{H}_{2} \mathrm{SO}_{4}$ ) and highly toxic salts (e.g., cyanide). The aim of the present work is to develop a coating of silver on copper substrate by electroless and electrolytic deposition methods from ionic liquids based on choline chloride and hydrogen bond donors such as ethylene glycol (EG) or urea.

\section{Materials and Methods}

Chemicals. Choline chloride $\left[\mathrm{HOC}_{2} \mathrm{H}_{4} \mathrm{~N}\left(\mathrm{CH}_{3}\right)_{3} \mathrm{Cl}\right](\mathrm{ChCl})$ (Aldrich 99\%) which was recrystallised from absolute ethanol, filtered and dried under vacuum. Urea (Aldrich $>99 \%$ ) was dried under vacuum prior to use. Ethylene glycol (EG) (Aldrich $>99 \%$ ), silver nitrate $\left(\mathrm{AgNO}_{3}\right)$ (Merck 99.8\%), and all other chemicals were used as received.

Preparation of ionic liquid. The eutectic mixtures were formed by stirring the two components together, in the stated proportions, at $75^{\circ} \mathrm{C}$ until a homogeneous, colourless liquid formed. The molar ratio for the eutectic compositions was found to be 1:2 for choline chloride $(\mathrm{ChCl})$ with ethylene glycol (EG) or urea. The ionic liquids, once formulated, were kept in a thermostatic oven at $30^{\circ} \mathrm{C}$ prior to use.

Electrochemical and analytical study. Electrochemical investigations including potential step chronoamperometry, chronopotentiometry and cyclic voltammetry were carried out using a Hokudo Denko HAB151 Potentiostat/ Galvanostat, Tokyo, Japan, equipped with a potential sweeper. Data were recorded in a computer through data acquisition system (USA) using WinDaq software. A threeelectrode system consisting of a platinum $\left(50 \times 5 \times 0.1 \mathrm{~mm}^{3}\right)$ working electrode, a silver $\left(50 \times 10 \times 0.2 \mathrm{~mm}^{3}\right)$ counter electrode and a silver wire quasi-reference electrode were used in all electro-chemical studies. The working electrode was cleaned electrochemically in $1.5 \mathrm{~mol} / \mathrm{dm}^{3} \mathrm{H}_{2} \mathrm{SO}_{4} 1.0$ $\mathrm{mol} / \mathrm{dm}^{3} \mathrm{H}_{3} \mathrm{PO}_{4}$ mixtures then rinsed with deionised water, and finally dried with acetone prior to use in all measurements. All voltammograms were obtained at $30^{\circ} \mathrm{C}$ with various scan rates ranging from 5 to $100 \mathrm{mV} / \mathrm{s}$. A silver wire (immersed in ethaline/reline) quasi-reference electrode was used in all electrochemical experiments which have been shown to have stable reference potential in chloride based eutectics. All potentials in this work are quoted with respect to $\mathrm{Ag} / 1: 2 \mathrm{ChCl}-\mathrm{EG} /$ urea reference electrode (which will be written as $\mathrm{Ag} / \mathrm{Ag}(\mathrm{I})$ (note that the reference potential will be changed slightly with melts of different compositions).

Deposition of silver. The electroless plating of silver were carried out in a glass beaker containing $15 \mathrm{~cm}^{3}$ ionic liquids at room temperature (typically $25 \sim 30{ }^{\circ} \mathrm{C}$ ) onto copper $\left(50 \times 10 \times 0.2 \mathrm{~mm}^{3}\right)$ or mild steel $\left(50 \times 10 \times 0.2 \mathrm{~mm}^{3}\right)$ substrates. Prior to deposition experiments, copper and steel substrates were mechanically polished to mirror finish by 600,1000 and 2000 grit sandpaper. After polishing, the specimens were ultrasonically cleaned in deionised water, and finally dried with acetone. The substrates were then immediately immersed in ChCl:2EG (ethaline) and $\mathrm{ChCl}$ :2Urea (reline) ionic liquids containing $\mathrm{AgNO}_{3}$ $\left(0.01 \sim 0.10 \mathrm{~mol} / \mathrm{dm}^{3}\right)$ at different time periods (1 5 $\left.\mathrm{min}\right)$. The electrolytic deposition of silver were carried out onto copper and steel cathodes under constant current and constant potential methods from ionic liquids (ethaline/ reline) containing $\mathrm{AgNO}_{3}$ at room temperature. Following each deposition, the resulting deposit was soaked firstly in ethanol, then in deionised water, and finally washed with acetone to remove the residual ionic liquids. The deposit was then dried with cold air.

Deposit characterisation. The surface morphologies of the samples were then examined with scanning electron microscope (XL 30 SEM, PHILIPS) and its auxiliary X-ray energy dispersive spectroscope (EDX). $\mathrm{X}$-ray diffraction analysis was also performed with a Philips PW 1716 diffractometer using $\mathrm{Cu} K_{\propto}$ radiation $(40 \mathrm{kV}, 25 \mathrm{~mA})$ to explore the crystal structure of the deposits.

\section{Results and Discussion}

Cyclic voltammetry of $\mathrm{Ag}(\mathrm{I})$ in $\mathrm{ChCl}$ :2EG (ethaline) and $\mathrm{ChCl}$ :2urea (reline) ionic liquids. The cyclic voltammograms recorded on a platinum electrode in 1:2:0.05 (mole ratio) $\mathrm{ChCl}: \mathrm{EG}: \mathrm{AgNO}_{3}$ (a) and $\mathrm{Ch} \mathrm{Cl}$ : urea: $\mathrm{AgNO}_{3}$ (b) ionic liquids at $30{ }^{\circ} \mathrm{C}$ with a scan rate of $10 \mathrm{mV} / \mathrm{s}$ are shown in Fig. 1. The rest potentials are $+0.44 \mathrm{~V}$ in ethaline and $+0.22 \mathrm{~V}$ in reline. The scan towards negative direction consists of first reduction waves $C_{1}$ in Fig. $1 \mathrm{a}$ and $\mathrm{C}_{1}^{\prime}$ in Fig. $1 \mathrm{~b}$ with the currents starting to increase at $-0.03 \mathrm{~V}\left(\mathrm{C}_{1}\right)$ and $+0.013 \mathrm{~V}\left(\mathrm{C}_{1}^{\prime}\right)$. Additional reduction waves $\mathrm{C}_{2}$ in Fig. $1 \mathrm{a}$ and $\mathrm{C}_{3}{ }_{3}$ in Fig. $1 \mathrm{~b}$ are observed with the currents increase starting 
again at $-1.10 \mathrm{~V}$ and $-1.00 \mathrm{~V}$, respectively. The reverse scan consists of first oxidation peaks $\mathrm{P}_{\mathrm{a} 1}$ in Fig. 1a $(+0.11 \mathrm{~V})$ and $\mathrm{p}_{\mathrm{a} 1}^{\prime}$ in Fig. $1 \mathrm{~b}(+0.146 \mathrm{~V})$. Additional oxidation waves are also observed with the currents starting to increase at $+1.02 \mathrm{~V}$ for ethaline and +0.90 $\mathrm{V}$ for reline. From XRD and EDX analyses, pure silver has been detected in the deposit obtained at a deposition potential of $-0.12 \mathrm{~V}$ (from the first reduction waves $\mathrm{C}_{1}$ and $\mathrm{C}_{1}$ ) by constant potential method. Therefore, the increases of the negative currents in the first reduction waves $\mathrm{C}_{1}$ and $\mathrm{C}_{1}$ are obviously associated with the reductions of silver ions to metallic state according to the following reaction.

$$
\mathrm{Ag}_{(\mathrm{ad})}^{+}+\mathrm{e}^{-} \rightarrow \mathrm{Ag}
$$
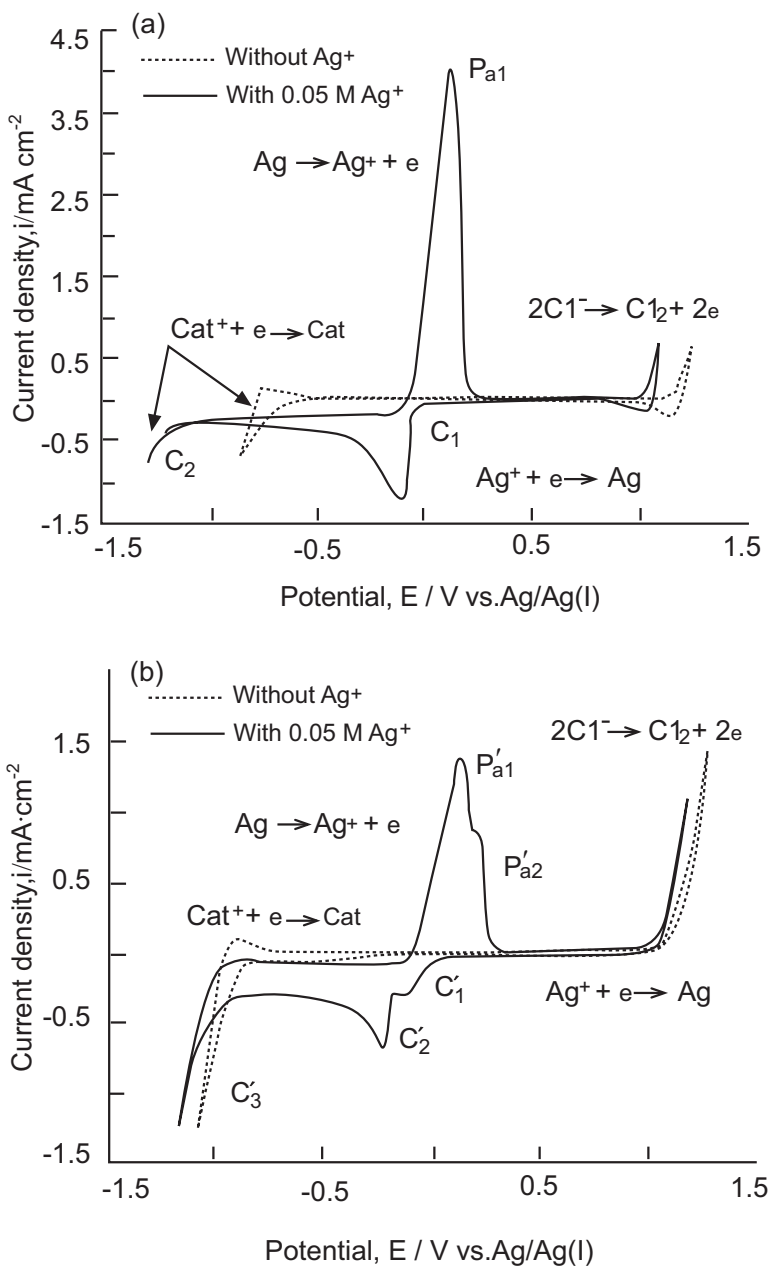

Fig. 1. Cyclic voltammograms recorded on a platinum electrode in $\mathrm{ChCl}: 2 \mathrm{EG}$ (a) and $\mathrm{ChCl}$ :2urea (b) ionic liquids containing $0.05 \mathrm{M} \mathrm{AgNO}_{3}$ at $30{ }^{\circ} \mathrm{C}$ with a scan rate of $10 \mathrm{mV} / \mathrm{s}$.
Compared with the voltammograms obtained in the absence of $\mathrm{AgNO}_{3}$, dotted curves in Fig.1a and Fig.1b, the reduction waves appeared at $-0.72 \mathrm{~V}$ in ethaline and $-0.90 \mathrm{~V}$ in reline correspond to the reduction of cationic species $\left(\mathrm{Cat}^{+}\right)$into these ionic liquids, while the oxidation waves appeared at $+1.2 \mathrm{~V}$ in ethaline and $+1.0 \mathrm{~V}$ in reline correspond to the oxidation of chloride ions (anions) to molecular/gaseous chlorine according to following reaction.

$$
2 \mathrm{Cl}_{(\mathrm{ad})}^{-} \rightarrow \mathrm{Cl}_{2} \uparrow+2 \mathrm{e}^{-}
$$

Figure 2 shows the effect of sweeping potentials on the cyclic voltammograms recorded on a platinum electrode in 1:2:0.05 (mole ratio) $\mathrm{ChCl}$ :urea: $\mathrm{AgNO}_{3}$ ionic liquids at $30{ }^{\circ} \mathrm{C}$ with a scan rate of $10 \mathrm{mV} / \mathrm{s}$. It is readily seen from the voltammograms that the first reduction wave $\mathrm{C}_{1}^{\prime}$ corresponds to the second oxidation peak $\mathrm{P}_{\mathrm{a} 2}^{\prime}$ and the second reduction wave $\mathrm{C}_{2}^{\prime}$ corresponds to the first oxidation peak $\mathrm{P}^{\prime}{ }_{\mathrm{a} 1}$. Pure silver has also been detected in the deposit obtained at a deposition potential of -0.12 $\mathrm{V}$ and $-0.22 \mathrm{~V}$ (from the first $\mathrm{C}_{1}{ }_{1}$ and second reduction waves $C_{2}^{\prime}$ ) by constant potential method. Therefore, the increases of the negative currents in the first and second reduction waves $\left(\mathrm{C}_{1}^{\prime}\right.$ and $\left.\mathrm{C}_{2}^{\prime}\right)$ are also associated with the reductions of silver ions to metallic state.

It can be seen from the voltammograms that more cathodic limits lead to increasing charge for more anodic dissolution process. The two reduction waves and two oxidation peaks

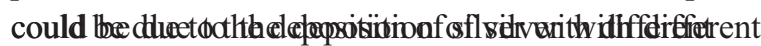

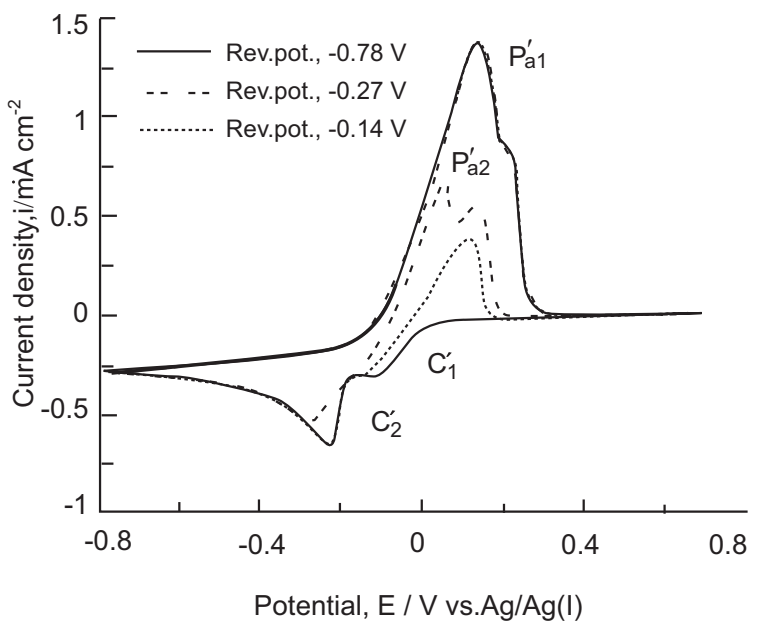

Fig. 2. Effect of sweeping potentials on the cyclic voltammograms recorded on a platinum electrode in $\mathrm{ChCl}$ :2urea ionic liquids containing $0.05 \mathrm{M} \mathrm{AgNO}_{3}$ at $30{ }^{\circ} \mathrm{C}$ with a scan rate of $10 \mathrm{mV} / \mathrm{s}$. 
morphologies (Fig. 2). The two different morphologies must result from different growth mechanisms. One possibility could be the initial growth of a large number of nuclei on the surface where some of which stop growing giving a material with a different morphology. Alternatively, some aspect of the interfacial layer structure could neutralise the surface energy of the growing particle. Similar morphology had been reported by Abbott et al. (2010) for the deposition of aluminium from chloroaluminate based ionic liquids.

Figure 3 shows the effect of $\mathrm{AgNO}_{3}$ concentrations on the cyclic voltammograms recorded on a platinum electrode in $\mathrm{ChCl}: 2 \mathrm{EG} \mathrm{(a)}$ and $\mathrm{ChCl}: 2$ urea (b) ionic liquids at $30{ }^{\circ} \mathrm{C}$ with a scan rate of $10 \mathrm{mV} / \mathrm{s}$. It is readily seen from the voltammograms that, the magnitudes of the current densities of first reduction waves $\mathrm{C}_{1}$ and $\mathrm{C}_{1}^{\prime}$,
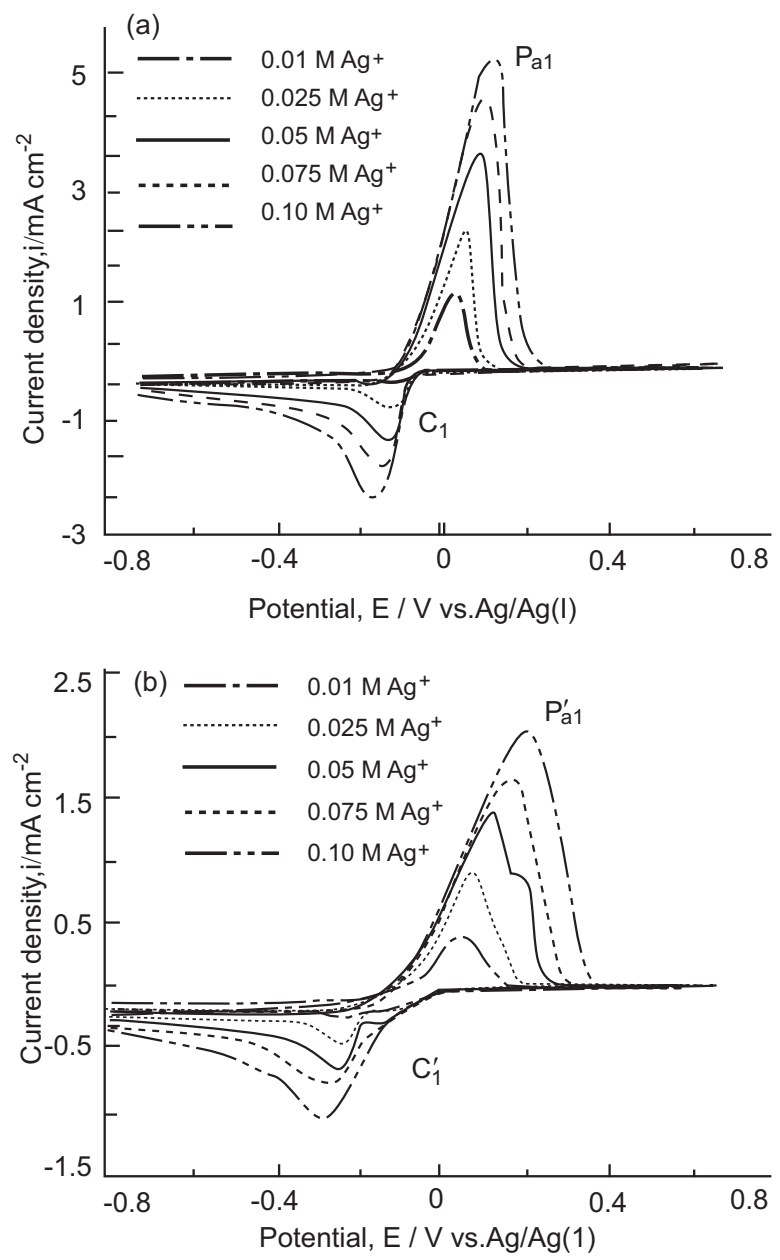

Fig. 3. Effect of $\mathrm{AgNO}_{3}$ concentrations on the cyclic voltammograms recorded on a platinum electrode in $\mathrm{ChCl}: 2 \mathrm{EG}$ (a) and $\mathrm{ChCl}$ :2urea (b) ionic liquids at $30{ }^{\circ} \mathrm{C}$ with a scan rate of $10 \mathrm{mV} / \mathrm{s}$. which are attributed to the reductions of silver ions to metallic silver, increase with the increase of the $\mathrm{AgNO}_{3}$ concentration added into the ionic liquids. The same phenomena are observed with the first oxidation peaks $\mathrm{P}^{\prime}{ }_{\mathrm{a} 1}$ (Fig. 3a) and $\mathrm{P}_{\mathrm{a} 1}^{\prime}$ (Fig. 3b), which also shows the increase in current densities with the increase of $\mathrm{AgNO}_{3}$ concentrations. As the magnitudes of the reduction current densities of silver $\left(\mathrm{C}_{1}\right.$ and $\left.\mathrm{C}_{1}\right)$ increase; the magnitudes of the oxidation peak current densities $\left(\mathrm{P}_{\mathrm{a} 1}\right.$ and $\left.\mathrm{P}_{\mathrm{a} 1}^{\prime}\right)$ also increase, therefore, it is concluded that the first oxidation peaks $\mathrm{P}_{\mathrm{a} 1}$ and $\mathrm{P}_{\mathrm{a} 1}^{\prime}$ are attributed to the dissolution of the deposited silver into this ionic liquid.

The effect of scan rates on the cyclic voltammograms recorded on a platinum electrode in ChCl: $2 \mathrm{EG}: 0.05 \mathrm{AgNO}_{3}$ (a) and ChCl:2urea: $0.05 \mathrm{AgNO}_{3}$ (b) ionic liquids at $30^{\circ} \mathrm{C}$ are presented in Fig. 4. For a reversible system, peak potential
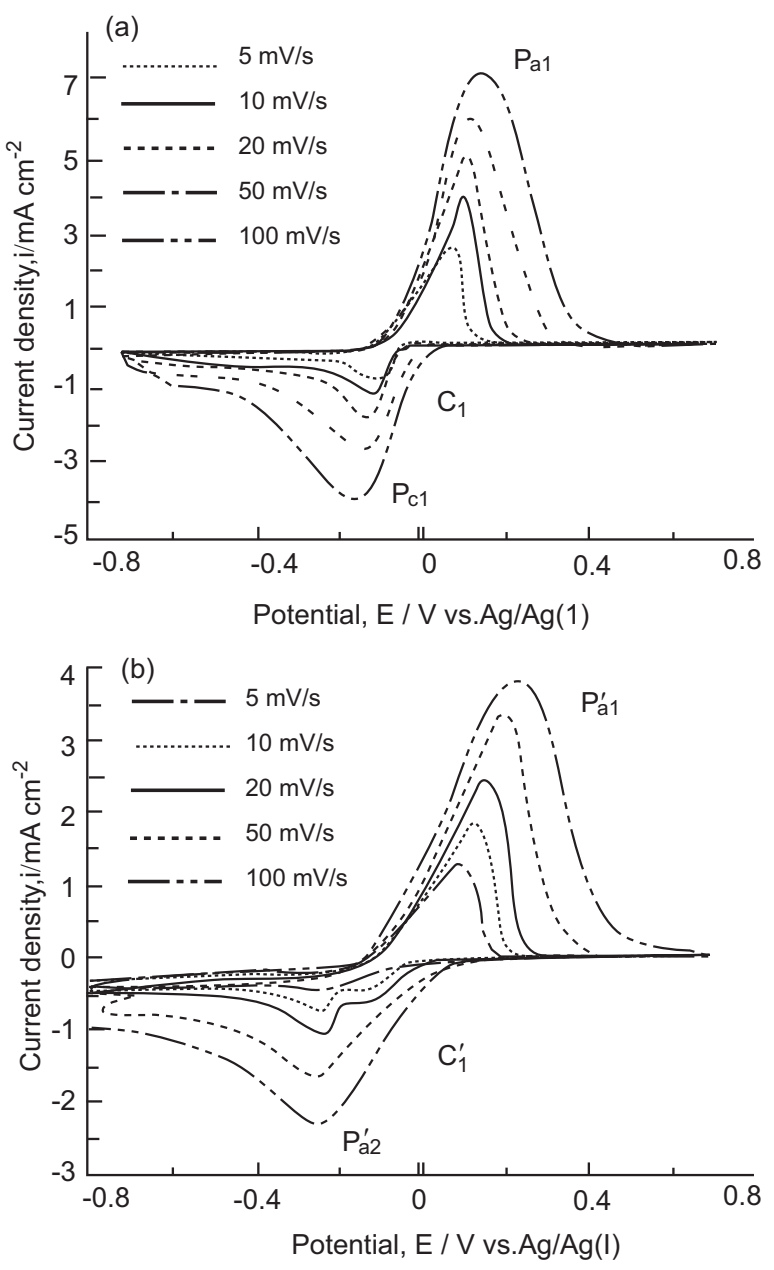

Fig. 4. Effect of scan rates on the cyclic voltammograms recorded on a platinum electrode in $\mathrm{ChCl}$ :2EG (a) and $\mathrm{ChCl}$ :2urea (b) ionic liquids containing $0.05 \mathrm{M} \mathrm{AgNO}_{3}$ at $30^{\circ} \mathrm{C}$. 
$E_{p}$ is independent of the scan rate $(v)$, and the peak current density $\left(i_{p}\right)$ is proportional to the square root of scan rate $\left(v^{1 / 2}\right)$. In the present study (Fig. $4 \mathrm{a}$ ), the cathodic peak potentials $\left(\mathrm{E}_{\mathrm{p} / \mathrm{c}}\right)$ are $-0.135,-0.14,-0.141,-0.142$ and -0.145 $\mathrm{V}$ for $5,10,20,50$ and $100 \mathrm{mV} / \mathrm{s}$ scan rates and the anodic peak potentials $\left(\mathrm{E}_{\mathrm{p} / \mathrm{c}}\right)$ are 0.095, 0.098, 0.10, 0.105 and $0.115 \mathrm{~V}$ for $5,10,20,50$ and $100 \mathrm{mV} / \mathrm{s}$ scan rates, respectively. In Fig. $4 b$, the cathodic peak potentials $\left(\mathrm{E}_{\mathrm{p} / \mathrm{c}}\right)$ are $-0.223,-0.224,-0.225,-0.23$ and $-0.24 \mathrm{~V}$ for $5,10,20$, 50 and $100 \mathrm{mV} / \mathrm{s}$ scan rates and the anodic peak potentials $\left(\mathrm{E}_{\mathrm{p} / \mathrm{a}}\right)$ are $0.13,0.14,0.15,0.20$ and $0.22 \mathrm{~V}$ for $5,10,20,50$ and $100 \mathrm{mV} / \mathrm{s}$ scan rates, respectively. It is evident from these results that the peak potentials for the reduction and oxidation waves of silver are almost independent of the scan rates indicating the systems are reversible in nature. Variations in peak current densities of $\mathrm{C}_{1}$ and $\mathrm{C}_{1}{ }_{1}$ with the square root of scan rate $\left(i_{p}\right.$ vs. $\left.v^{1 / 2}\right)$ are shown in Fig. 5. For a reversible system, the relationship between the cathodic peak current density $i_{p}$ and the square root of the scan rate $V^{1 / 2}$ is given by Baird and Faulkner (1980):

$$
\mathrm{i}_{\mathrm{p}}=\left(2.69 \times 10^{5}\right) \mathrm{n} 3^{/ 2} \cdot \mathrm{A} \cdot \mathrm{D}_{\mathrm{Ag}(\mathrm{I})}^{1 / 2} \cdot \mathrm{C}_{\mathrm{Ag}(\mathrm{I})} \cdot V^{1 / 2}
$$

where:

$\mathrm{C}_{\mathrm{Ag}(\mathrm{I})^{*}}=$ the concentration of silver ions in the bulk solution, $\mathrm{D}=$ the diffusion coefficient of silver ions, $A=$ the surface area of the electrode, $n=$ the number of electron transferred during reduction reaction and $V$ the scan rate. The linear increases in the peak current densities of $\mathrm{C}_{1}$ and $\mathrm{C}_{1}$ with the square root of scan rate,

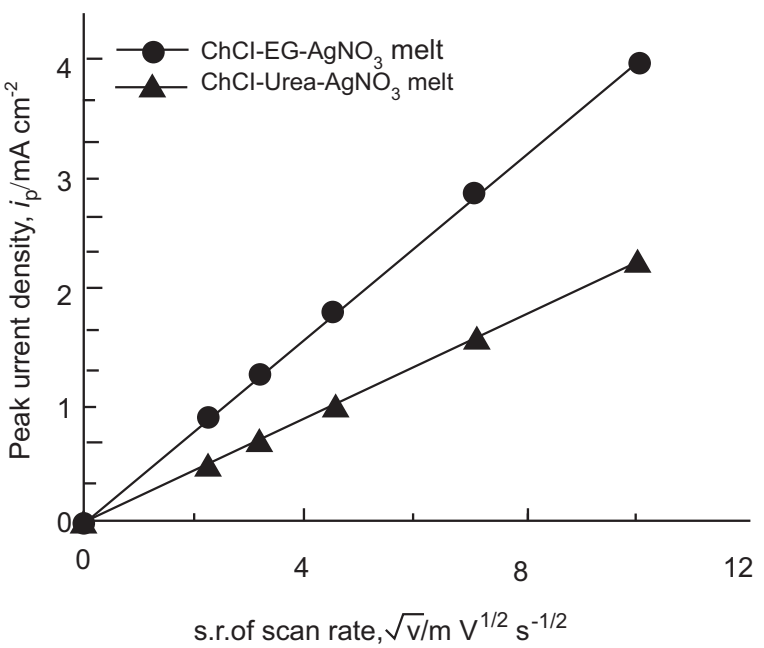

Fig. 5. Variations in cathodic peak current densities with the square root of scan rate for the reduction of silver ions in ethaline (a) and reline (b) containing $0.05 \mathrm{M} \mathrm{AgNO}_{3}$. as shown in Fig. 5, indicate that the reduction processes of silver ions in both $\mathrm{ChCl}: 2 \mathrm{EG}$ and $\mathrm{ChCl}$ :2urea based ionic liquids are controlled by diffusion.

Electroless deposition of silver from ethaline and reline. The camera images of electroless deposited silver layer obtained from both ethaline and reline based ionic liquids at different immersion time and different $\mathrm{AgNO}_{3}$ concentrations are shown in Fig. 6. The deposits are smooth, shiny, and good adherence. The deposits are not peeling off by hand scratching. The scanning electron micrographs of silver electroless deposits obtained from 1:2:0.05 (mole ratio) $\mathrm{ChCl}: \mathrm{EG}: \mathrm{AgNO}_{3}$ and $\mathrm{ChCl}$ : urea: $\mathrm{AgNO}_{3}$ at $30{ }^{\circ} \mathrm{C}$ are shown in Fig. 7. The SEM images show that the surfaces are free from crack. Fig. 8a and $8 \mathrm{~b}$ show the EDX profile for the SEM images of Figs $7 \mathrm{a}$ and $7 \mathrm{~b}$, respectively. Pure silver has been detected in the deposited layer by EDX analysis. There is no spectrum for residual chloride ions in the EDX profile indicate no incorporation of the ionic liquid in the deposits. Therefore, it is concluded that eutectic based ionic liquids of $\mathrm{ChCl}: 2 \mathrm{EG}$ (ethaline) and $\mathrm{ChCl}$ :2urea (reline) can be used for the electroless deposition of bright metallic colour silver on a metallic substrate.

Electrodeposition of silver from ethaline and reline. Silver electrodeposition experiments have been carried out on steel and copper cathodes under constant potential and constant current methods from both EG and urea based ionic liquids at room temperature. All of the electrodeposits obtained on $\mathrm{Pt}$ and $\mathrm{Cu}$ substrates at the applied deposition potentials ranging from -0.20 to $-0.40 \mathrm{~V}$ and the applied deposition current densities ranging from -1.0 to $-5.0 \mathrm{~A} / \mathrm{m}^{2}$ appear to be smooth and silver metallic colour. There is no apparent rupture on the deposit surface and the deposits do not peeling off by hand scratching. However, the
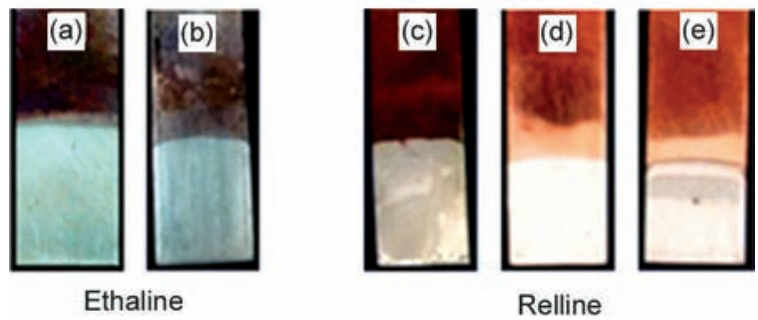

Fig. 6. Camera images of silver electroless deposits on copper substrates obtained from ethaline (a, b) and reline (c, d, e) containing $0.10 \mathrm{M}$ $\mathrm{AgNO}_{3}$ at $30^{\circ} \mathrm{C}$. Immersion time: a, b, c, $4 \mathrm{~min}$; $\mathrm{d}, 2 \mathrm{~min}$ and e, $1 \mathrm{~min}$. 


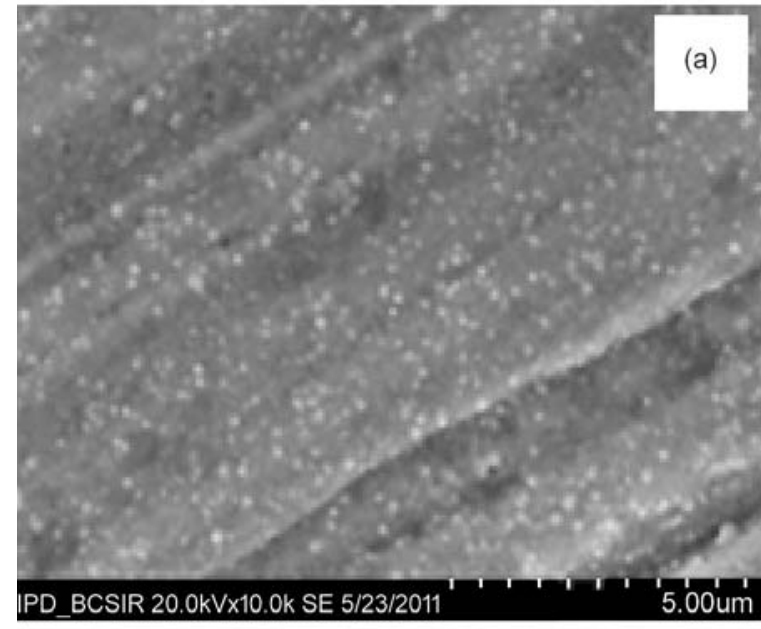

(b)

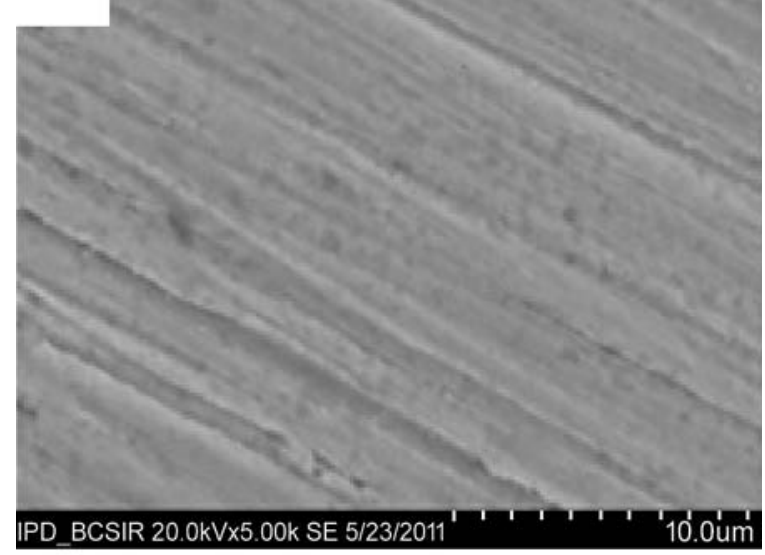

Fig. 7. SEM images of silver electroless deposits on $\mathrm{Cu}$ substrates obtained from mole ratios of 1:2:0.05 in ChCl:EG: $\mathrm{AgNO}_{3}$ (a) and ChCl:urea: $\mathrm{AgNO}_{3}$ (b) ionic liquids at $30{ }^{\circ} \mathrm{C}$. Immersion time: (a) $3 \mathrm{~min}$ and (b) 5 min.

deposits obtained at the applied deposition potential of $-0.60 \mathrm{~V}$ are not smooth due to high deposition over potential. The SEM images of the electrodeposited silver layer on copper cathodes under constant potential method from both EG and urea based ionic liquids are shown in Fig. 9. The electrodeposited crystals are angular and also nodular in shape and in the order of $1 \sim 3 \mu \mathrm{m}$ in size. From SEM images it is clear that the crystal sizes in the electrodeposited thin films are bigger than the electroless deposited thin films. However, it is difficult to get thick coating in electroless method. The thickness of the deposited layers is approximately $4 \sim 6 \mu \mathrm{m}$, which has been controlled by adjusting the total charge applied.
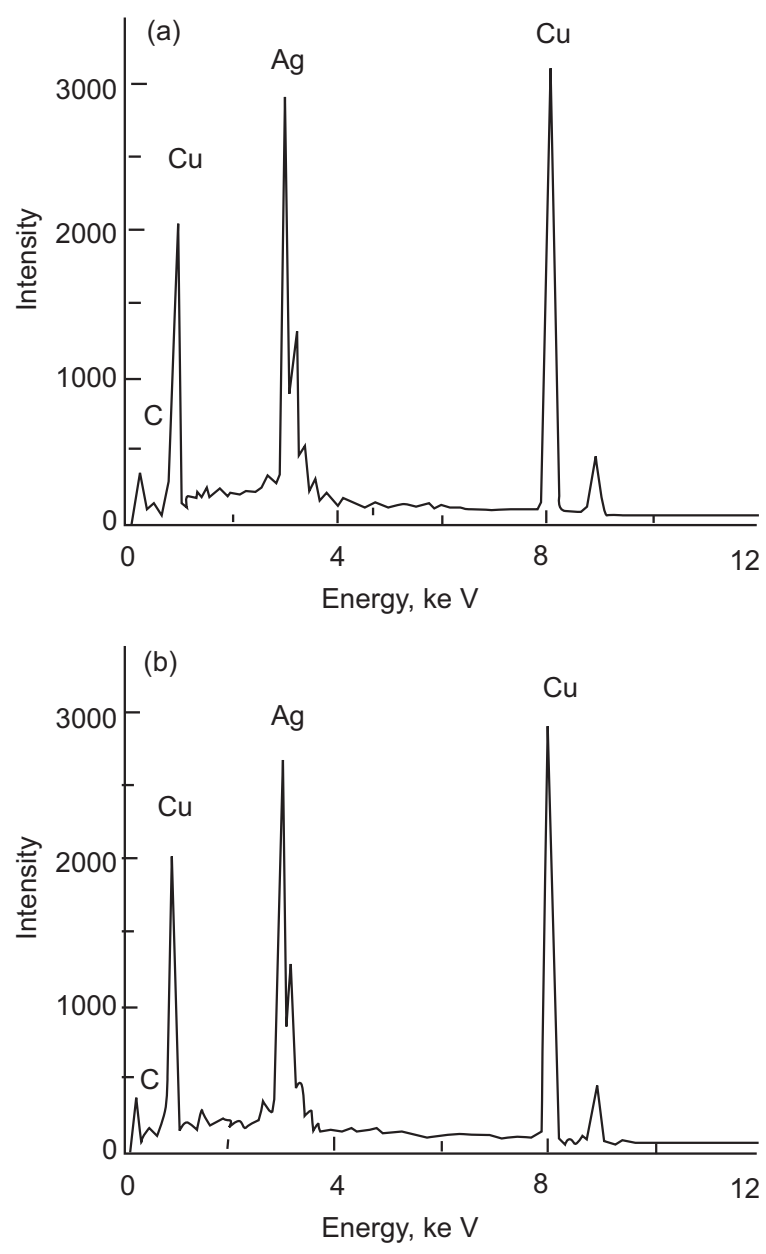

Fig. 8. EDX profile for the SEM images of Figs 7 (a) and 7(b).

The acquired diffraction patterns for the deposits obtained from mole ratios of 1:2:0.05 in ChCl:urea: $\mathrm{AgNO}_{3}$ ionic liquids at applied deposition potential of $-0.25 \mathrm{~V}$ is shown in Fig. 10. The diffraction peaks at $2 \theta=38.1^{\circ}, 44.3^{\circ}$, 64.4 ${ }^{\circ}$, and $77.4^{\circ}$ are for $\mathrm{Ag}(111), \mathrm{Ag}(200), \mathrm{Ag}$ (220) and $\mathrm{Ag}$ (311), respectively. The diffraction peaks are very sharp, indicating the deposit has the crystalline structure. The current efficiency for the deposition of pure silver is about $99 \%$. However, additional diffraction peaks at $2 \theta$ $=43.3^{\circ}, 50.45^{\circ}$, and $74.1^{\circ}$ corresponding to copper (substrate) are also observed in Fig. 10.

\section{Conclusion}

This work shows that the ionic liquids based on eutectic mixtures of choline chloride and hydrogen bond donors such as ethylene glycol or urea can be used as electrochemical solvents. Crack free smooth and bright metallic coloured silver can be electroless and electrolytic deposited onto steel and copper cathodes from ethaline and reline 

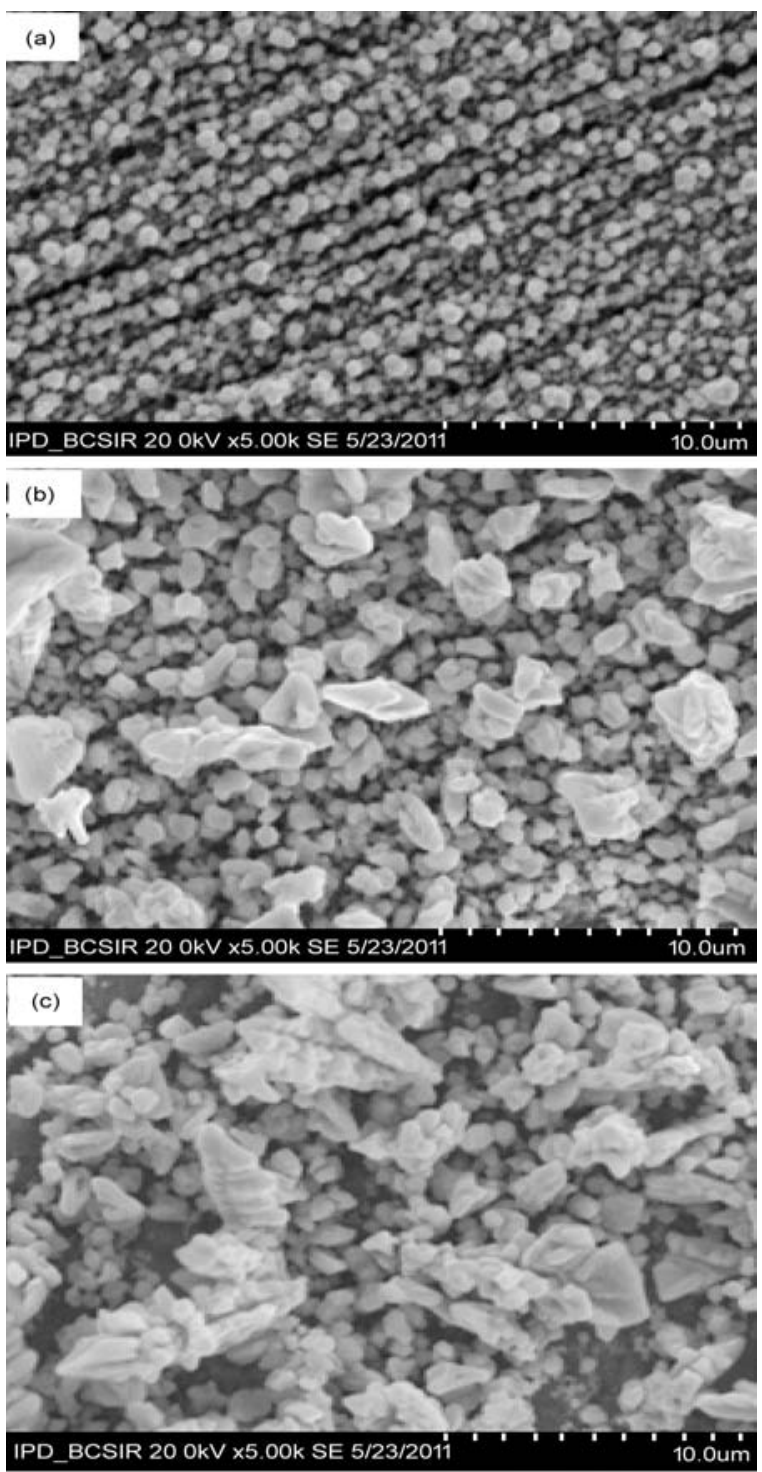

Fig. 9. SEM images of silver electroless deposits on $\mathrm{Cu}$ cathodes obtained from ethaline (a, c) and reline (b) ionic liquids containing $0.05 \mathrm{M} \mathrm{AgNO}_{3}$ at $30{ }^{\circ} \mathrm{C}$. Applied deposition potential: (a) $-0.20 \mathrm{~V}$, (b) -0.25 $\mathrm{V}$ and $(\mathrm{c})-0.30 \mathrm{~V}$.

based ionic liquids containing $\mathrm{AgNO}_{3}$ at room temperature. The silver electrodeposits obtained at the applied deposition potentials up to $-0.40 \mathrm{~V}$ and applied deposition current densities up to $-5.0 \mathrm{~A} / \mathrm{m}^{2}$ are smooth and bright metallic colour.

\section{Acknowledgement}

The authors gratefully acknowledge the Ministry of Science and Technology, Government of the People's

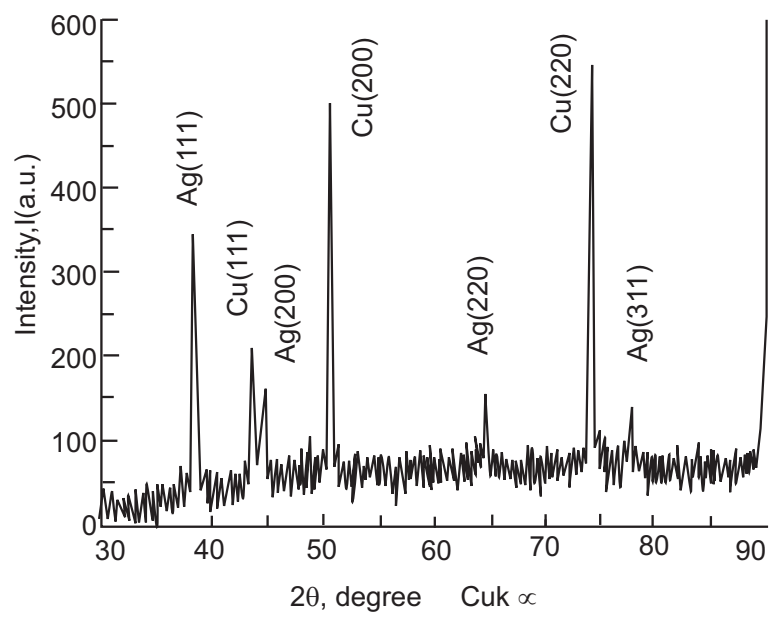

Fig. 10. X-ray diffraction pattern of silver electrodeposit obtained on copper from mole ratios of 1:2: 0.05 in $\mathrm{ChCl}$ : urea: $\mathrm{AgNO}_{3}$ ionic liquid at $30{ }^{\circ} \mathrm{C}$ and $-0.25 \mathrm{~V}$.

Republic of Bangladesh for financial support to carry out this work. Part of the study has been presented at the $6^{\text {th }}$ Japan-China joint seminar on Marine Corrosion and Control, held at Tokyo Institute of Technology, Tokyo, Japan on $2^{\text {nd }}$ March, 2012.

\section{References}

Abbott, A.P., Fulian, Q., Abood, H.M.A., Ali, M.R., Ryder, K.S. 2010. Double layer, diluent and anode effects upon the electrodeposition of aluminium from chloroaluminate based ionic liquids. Physical Chemistry Chemical Physics, 12: 1862-1872.

Abbott, A.P., McKenzie, K.J. 2006. Application of ionic liquids to the electrodeposition of metals. Physical Chemistry Chemical Physics, 8: 4265-4279.

Abbott, A.P., Capper, G., McKenzie, K.J., Glidle, A., Ryder, K.S. 2006a. Electropolishing of stainless steels in a choline chloride based ionic liquid: an electrochemical study with surface characterisation using SEM and atomic force microscopy. Physical Chemistry Chemical Physics, 8: 4214-4221.

Abbott, A.P., Capper, G., McKenzie, K.J., Ryder, K.S. 2006b. Voltammetric and impedance studies of the electropolishing of type 316 stainless steel in choline chloride based ionic liquid. Electrochimica Acta, 51: 4420-4425.

Abbott, A.P., Capper, G., Davies, D.L., Rasheed, R.K. 2004a. Ionic liquid analogues formed from hydrated metal salts. Chemistry, 10: 3769-3774.

Abbott, A.P., Boothby, D., Capper, G., Davies, D.L., 
Rasheed, R.K. 2004b. Deep eutectic solvents formed between choline chloride and carboxylic acids: Versatile alternatives to ionic liquids. Journal of American Chemical Society, 126: 91429147.

Abbott, A.P., Capper, G., Davies, D.L., Rasheed, R.K., Tambyrajah,V. 2003. Novel solvent properties of choline chloride/urea mixtures. Chemical Communications, 7: 70-71.

Baird, A.J., Faulkner, L.R. 1980. Electrochemical Methods: Fundamentals and Applications, 218 pp., John Wiley \& Sons, New York, USA.

Djokic, S.S. 2002. Electroless deposition of metals and alloys. In: Modern Aspects of Electrochemistry,
B.E. Conway and R.E. White (eds.), vol. 1, pp. 51133, Springer, USA

Endres, F. 2002. Ionic liquids: Solvents for the electrodeposition of metals and semiconductors. Chemphyschem: A European Journal of Chemical Physics and Physical Chemistry, 3: 145-154.

Ohno, H. (ed.). 2005. Electrochemical Aspects of Ionic Liquids, 408 pp., John Wiley \& Sons, New York, USA.

Shipley, C.R. 1961. US Patent 3, 011, 920.

Sun, J., MacFarlane, D.R., Forsyth, M. 2003. A new family of ionic liquids based on the 1-alkyl-2-methyl pyrrolinium cation. Electrochimica Acta, 48: 17071711. 